\title{
Variabilidade espacial e temporal da precipitação pluvial no município do Rio de Janeiro
}

\author{
Willian Campos Sicilianol; Giovana Proença Bastos ; Israel Tiago de Oliveiral; Gabrielle Nunes da \\ Silval; Marcelo Obraczkal; Alfredo Akira Ohnuma $\mathrm{Jr}^{\mathrm{l}}$
}

giovana_proenca@hotmail.com

1. Universidade do Estado do Rio de Janeiro, Maracanã, Rio de Janeiro, Brasil.

Histórico do Artigo:

Recebido em: 20 de abril de $2018 \quad$ Aceito em: 08 de agosto de 2018 Publicado em: 28 de dezembro de 2018

Resumo: Este artigo analisa o comportamento do regime de chuvas, distribuído no município do Rio de Janeiro, a partir de dados observados em mais de 30 estações pluviométricas monitoradas pelo Sistema Alerta Rio da Prefeitura do Rio de Janeiro (SAR-RJ), entre os anos de 1997 e 2014. Na análise da variação temporal e espacial da precipitação no município é possível identificar possíveis tendências e padrões do volume precipitado em função da sazonalidade e localidade. 0 estudo se baseia na confeç̧ão de mapas de isoietas mensais, obtidos pelo programa Surfer 10, cuja representação gráfica das características pluviométricas de cada região é analisada mediante determinados fatores ambientais como relevo, clima e estações do ano. 0s resultados evidenciam índices pluviométricos acentuados em todo o município e de forma concentrada no período entre outubro e abril. Conclui-se que regiões como Barra/Barrinha, Alto da Boa vista, Tijuca, Jardim Botânico, Rocinha e Vidigal apresentam precipitações mensais superiores aos demais locais, independente do período, devido a presença de áreas verdes preservadas e fatores climáticos variados. A padronização das chuvas na cidade do Rio de Janeiro está diretamente associada a fatores ambientais como uso e ocupação do solo, relevos de maciços geográficos e região oceânica.

Palavras-chave: precipitação; variabilidade e isoietas.

\section{Spatial and temporal variability of rainfall in the city of Rio de Janeiro}

\begin{abstract}
This article analyzes the rainfall regime behavior, distributed in the city of Rio de Janeiro, based on observed data more than 30 rainfall stations followed by Sistema Alerta Rio da Prefeitura do Rio de Janeiro (SARRJ), from 1997 to 2014. When analyzing the spatial and temporal variability of rainfall in the city, it is possible identify some trends and patterns of the volume of rainfall according to the seasonality as well as the locality. This study consists to elaborate monthly isohyetal maps, provided by Surfer 10 software, whose graphical representation of each region is analyzed through certain environmental factors such as topography, weather and seasons of the year. The results show high rainfall rates on the city and concentrated between October and April. This article concludes that regions such as Barra/Barrinha, Alto da Boa Vista, Tijuca, Jardim Botânico, Rocinha and Vidigal present rainfall rates higher than other regions, regardless of the period of the year, due to existence of preserved green areas and different climatic factors. The rainfall pattern in the city of Rio de Janeiro is directly connected to environmental factors such as land use/cover, mountain massifs and coastal region. Keywords: rainfall; variability and isohyets.
\end{abstract}




\title{
Variabilidad espacial y temporal de la precipitación pluvial en el municipio de Rio de Janeiro
}

\begin{abstract}
Resumen: Este artículo analiza el comportamiento del régimen de lluvias, distribuido en el municipio de Rio de Janeiro, a partir de datos observados en más de 30 estaciones pluviométricas monitoreadas por el Sistema de Alerta Rio da Prefeitura de Rio de Janeiro (SAR-RJ), entre los años de 1997 y 2014. En el análisis de la variación temporal y espacial de la precipitación en el municipio es posible identificar posibles tendencias y patrones del volumen precipitado en función de la estacionalidad y la localidad. El estudio se basa en la confección de mapas de isoietas mensuales, obtenidos por el programa Surfer 10, cuya representación gráfica de las características pluviométricas de cada región es analizada bajo determinados factores ambientales como el relieve, el clima y las estaciones del año. Los resultados evidencian índices pluviométricos acentuado en todo el municipio y de manera concentrada en el período entre octubre y abril. Se concluye que regiones como Barra/Barrinha, Alto da Boa vista, en el barrio de Tijuca, el Jardim Botânico, Rocinha y Vidigal presentan precipitaciones mensuales superiores los demás locales, independientemente del período, debido a la presencia de áreas verdes conservadas y factores climáticos variados. La estandarización de las lluvias en la ciudad de Rio de Janeiro está directamente asociada a factores ambientales como el uso y ocupación del suelo, los relieves de los macizos geográficos y la región oceánica.
\end{abstract}

Palabras clave: precipitación; la variabilidad y isoietas.

\section{INTRODUÇÃO}

De modo geral, a variabilidade climática é responsável por influenciar o comportamento da população, além de determinados setores da economia, sobretudo no consumo e geração de energia e nas atividades agropecuárias. Um dos elementos das alterações do clima é a variabilidade ou padronização da precipitação pluvial, como variável climática extremamente influente na qualidade ambiental (BRITTO; BARLETTA; MENDONÇA, 2006).

0 estudo de padrões de chuvas torna-se fundamental, à medida que se obtém dados observados de determinadas estações pluviométricas, cujas características interferem no planejamento de atividades agrícolas, na gestão de recursos hídricos, e em estudos climatológicos, quando analisados os volumes precipitados e a respectiva distribuição conjugada no tempo e no espaço (RADHA \& SUDHAKARAN, 2015).

Nas análises da distribuição e representação temporal e espacial das chuvas, os dados de precipitação pluviométrica são obtidos a partir da coleta de registros de séries históricas de estações pluviométricas localizadas em regiões de interesse ambiental (COSTA; MARCUZZO; FERREIRA; ANDRADE, 2012).

A representação gráfica internacionalmente utilizada consiste do traçado de linhas curvas unidas em pontos de mesma precipitação, cuja espacialidade apresenta regiões de 
Variabilidade espacial e temporal da precipitação pluvial no município do Rio de Janeiro

mesmo padrão no volume de chuvas. 0 método do traçado de isoietas informa o regime pluviométrico da região como possibilidade de conhecer a distribuição das chuvas em determinada época do ano.

Com peculiaridades na região, a cidade do Rio de Janeiro apresenta-se como uma metrópole que possui uma das maiores manchas urbanas do Brasil, além de situar um dos maiores centros econômicos e culturais da América Latina. Em função da importância da cidade no contexto nacional, o estudo do regime pluviométrico no município do Rio de Janeiro é de extrema utilidade ao seu desenvolvimento, sobretudo também por existir poucas referências sobre climatologia na região com base em longas séries de dados observacionais, sendo a maioria desenvolvida nas décadas de 1950 e 1970 (DERECZYNSKI; DE OLIVEIRA; MACHAD0, 2009). Análises de séries temporais da precipitação pluviométrica são consideradas metodologias capazes de identificar e distinguir possíveis efeitos sazonais e de tendência (ARAÚJ0 et al., 2009).

Variações dos totais anuais pluviométricos entre $1200 \mathrm{~mm}$ e $1600 \mathrm{~mm}$ ocorrem junto ao litoral da Zona Sul do município do Rio de Janeiro e nas proximidades do maciço da Tijuca. Ao norte do município, a distribuição dos totais anuais precipitados varia entre $1000 \mathrm{~mm}$ e $1400 \mathrm{~mm}$, com grande variabilidade espacial da precipitação observada nos maciços de Gericinó-Mendanha e da Pedra Branca, respectivamente, ao norte e oeste do município (SERRA, 1970 e DERECZYNSKI; DE OLIVEIRA; MACHAD0, 2009).

Este artigo visa analisar o comportamento pluviométrico distribuído no município do Rio de Janeiro de forma temporal e espacial baseado em série histórica de 18 anos de estações localizadas estrategicamente na região.

\section{MATERIAL E MÉTODOS}

A cidade do Rio de Janeiro situa-se na Região Sudeste do Brasil entre os paralelos $22^{\circ}$ 45' $05^{\prime}$ ' S e $23^{\circ}$ 04' 10" $\mathrm{S}$ e os meridianos $43^{\circ} 06^{\prime} 30^{\prime \prime} \mathrm{W}$ e $43^{\circ} 47^{\prime} 40^{\prime \prime W}$ (DERECZYNSKI; DE OLIVEIRA; MACHAD0, 2009) com área territorial de 1197,46 km² e população de 6.498 .837 habitantes (IBGE, 2016).

Constituída por acidentes geográficos variados, a cidade do Rio assenta-se sobre três grandes maciços da Pedra Branca, Gericinó e da Tijuca, de modo que caracterizam diferenças de altitude integradas à paisagem urbana. De clima equatorial com inverno seco ou tropical 
atlântico, conforme a classificação Koppen-Geiger (KOTTEL et al., 2006), a cidade apresenta amplitudes térmicas relativamente baixas, com verões quentes e úmidos, sobretudo por se situar em região litorânea com remanescentes de Mata Atlântica.

Na análise dos dados pluviométricos foram utilizadas as estações do Sistema Alerta Rio da Prefeitura do Rio de Janeiro (SAR-RJ) entre os anos de 1997 e 2014. Ao todo o SAR-RJ possui 33 estações telemétricas distribuídas no município de forma estratégica, sendo 26 pluviométricas e 7 meteorológicas (Tabela 1).

Tabela 1: Coordenadas geográficas das estações pluviométricas.

\begin{tabular}{|c|c|c|c|c|c|}
\hline $\mathrm{N}$ & Estação & Long. (W) & Lat. (S) & Elevação (m) & Período de Dados \\
\hline 1 & Vidigal & $-43,23306^{\circ}$ & $-22,99250^{\circ}$ & 85,0 & $1997-2014$ \\
\hline 2 & Urca & $-43,16667^{\circ}$ & $-22,95583^{\circ}$ & 90,0 & $1997-2014$ \\
\hline 3 & Rocinha & $-43,24500^{\circ}$ & $-22,98583^{\circ}$ & 160,0 & 1997-2014 \\
\hline 4 & Tijuca & $-43,22167^{\circ}$ & $-22,93194^{\circ}$ & 340,0 & 1997-2014 \\
\hline 5 & Santa Teresa & $-43,19639^{\circ}$ & $-22,93167^{\circ}$ & 170,0 & 1997-2014 \\
\hline 6 & Copacabana & $-43,18944^{\circ}$ & $-22,98639^{\circ}$ & 90,0 & 1997-2014 \\
\hline 7 & Grajaú & $-43,26750^{\circ}$ & $-22,92222^{\circ}$ & 80,0 & 1997-2014 \\
\hline 8 & Ilha do Governador & $-43,21028^{\circ}$ & $-22,81806^{\circ}$ & 0,0 & $1997-2014$ \\
\hline 9 & Penha & $-43,27528^{\circ}$ & $-22,84444^{\circ}$ & 111,0 & $1997-2014$ \\
\hline 10 & Madureira & $-43,33889^{\circ}$ & $-22,87333^{\circ}$ & 45,0 & $1997-2014$ \\
\hline 11 & Irajá & $-43,33694^{\circ}$ & $-22,82694^{\circ}$ & 20,0 & $1997-2014$ \\
\hline 12 & Bangu & $-43,46583^{\circ}$ & $-22,88028^{\circ}$ & 15,0 & $1997-2014$ \\
\hline 13 & Piedade & $-43,30722^{\circ}$ & $-22,89306^{\circ}$ & 72,0 & 1997-2014 \\
\hline 14 & Jacarepaguá/Tanque & $-43,36472^{\circ}$ & $-22,91250^{\circ}$ & 73,0 & $1997-2014$ \\
\hline 15 & Saúde & $-43,19444^{\circ}$ & $-22,89806^{\circ}$ & 35,0 & $1997-2014$ \\
\hline 16 & Jardim Botânico & $-43,22389^{\circ}$ & $-22,97278^{\circ}$ & 0,0 & 1997-2014 \\
\hline 17 & Barra/Itanhangá & $-43,29965^{\circ}$ & $-23,00849^{\circ}$ & 7,0 & $1997-2014$ \\
\hline 18 & Jacarep./Cidade de Deus & $-43,36278^{\circ}$ & $-22,94556^{\circ}$ & 15,0 & 1997-2014 \\
\hline 19 & Barra/Riocentro & $-43,40508^{\circ}$ & $-22,98129^{\circ}$ & 0,0 & 1997-2014 \\
\hline 20 & Guaratiba & $-43,59472^{\circ}$ & $-23,05028^{\circ}$ & 0,0 & 1997-2014 \\
\hline 21 & Est. Grajaú/Jacarepaguá & $-43,31583^{\circ}$ & $-22,92556^{\circ}$ & 105,0 & $2010-2014$ \\
\hline 22 & Santa Cruz & $-43,68444^{\circ}$ & $-22,90944^{\circ}$ & 15,0 & $1997-2014$ \\
\hline 23 & Grande Méier & $-43,27806^{\circ}$ & $-22,89056^{\circ}$ & 25,0 & $1997-2014$ \\
\hline 24 & Anchieta & $-43,40333^{\circ}$ & $-22,82694^{\circ}$ & 50,0 & $1997-2014$ \\
\hline 25 & Grota Funda & $-43,51944^{\circ}$ & $-23,01444^{\circ}$ & 10,0 & $1997-2014$ \\
\hline 26 & Campo Grande & $-43,56194^{\circ}$ & $-22,90361^{\circ}$ & 30,0 & $1997-2014$ \\
\hline 27 & Sepetiba & $-43,71167^{\circ}$ & $-22,96889^{\circ}$ & 62,0 & $1997-2014$ \\
\hline 28 & Alto da Boa Vista & $-43,27833^{\circ}$ & $-22,96583^{\circ}$ & 355,0 & 2011-2014 \\
\hline 29 & Av. Brasil/Mendanha & $-43,54111^{\circ}$ & $-22,85694^{\circ}$ & 30,0 & 2011-2014 \\
\hline
\end{tabular}


Variabilidade espacial e temporal da precipitação pluvial no município do Rio de Janeiro

\begin{tabular}{ccc|c|c|c}
\hline $\mathrm{N}$ & Estação & Long. (W) & Lat. (S) & Elevação (m) & Período de Dados \\
\hline 30 & Recreio dos Bandeirantes & $-43,44056^{\circ}$ & $-23,01000^{\circ}$ & 10,0 & $1997-2014$ \\
31 & Laranjeiras & $-43,18750^{\circ}$ & $-22,94056^{\circ}$ & 60,0 & $2001-2014$ \\
32 & São Cristóvão & $-43,22167^{\circ}$ & $-22,89667^{\circ}$ & 25,0 & $2001-2014$ \\
33 & Tijuca/Muda & $-43,24333^{\circ}$ & $-22,93278^{\circ}$ & 31,0 & $2012-2014$
\end{tabular}

Fonte: ALERTA RI0, 2017.

$\mathrm{Na}$ análise dos dados, as séries históricas apresentam períodos distintos, devido a posterior instalação dos pluviômetros das estações Grajaú/Jacarepaguá (21), Alto da Boa Vista (28), Av. Brasil/Mendanha (29), Laranjeiras (31), São Cristóvão (32) e Tijuca/Muda (33), entre 2001 e 2011.

Na implantação a partir do decreto $\mathrm{n}^{0}$ 15142/1996, o SAR-RJ tem como característica principal monitorar a precipitação em tempo real e emitir boletins de alerta à população à medida que se observam chuvas intensas e possibilidade de deslizamento de encostas (ALERTA RI0, 2017).

A localização geográfica dos postos de medição das chuvas pelo Sistema Alerta Rio é observada na Figura 1, com as características topográficas da região apresentadas no mapa em detalhe pelas curvas hipsométricas (PMRJ, 2011).
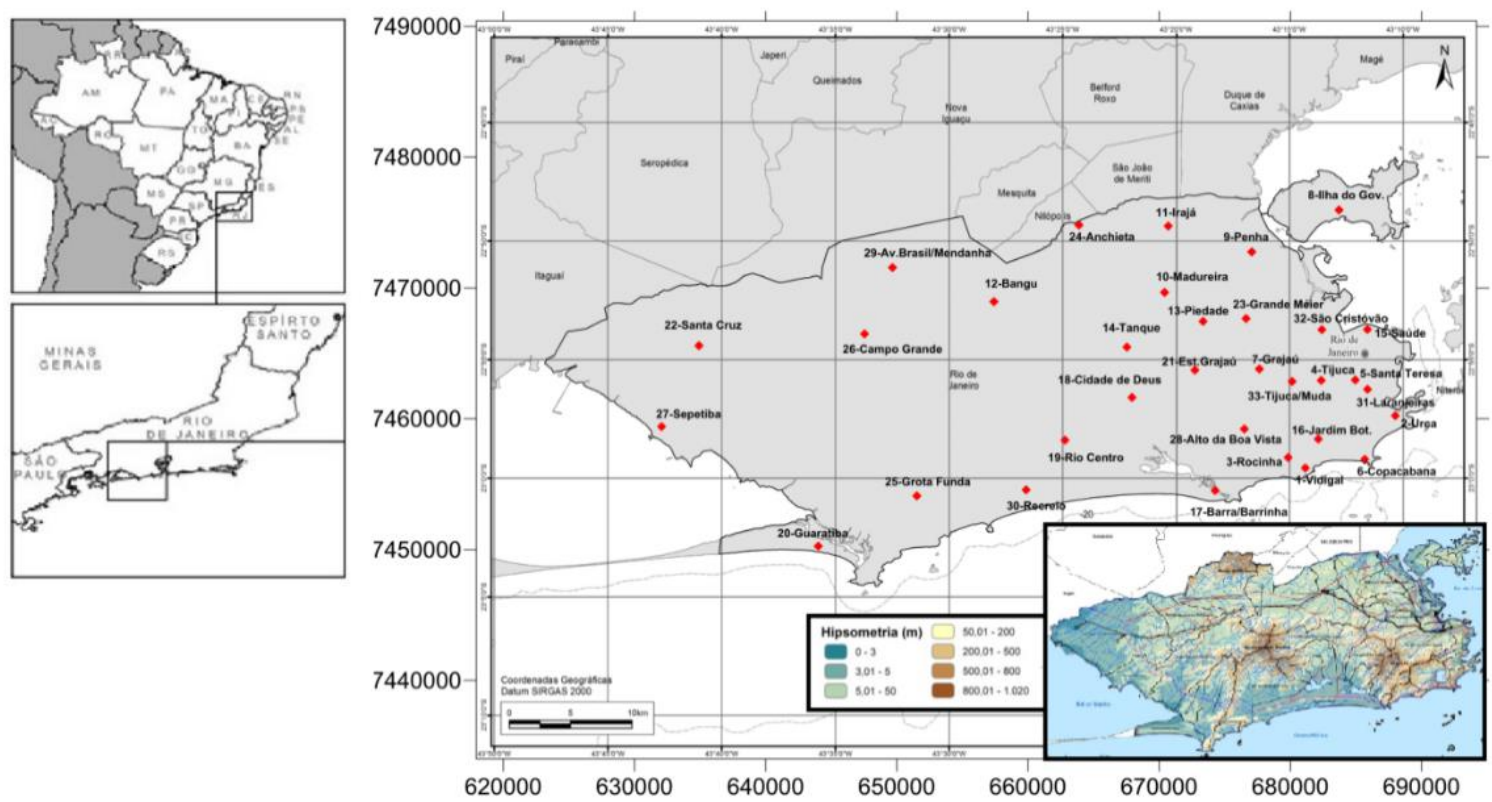

Figura 1- Localização das estações pluviométricas e detalhe hipsométrico da cidade do Rio de Janeiro.

Fonte: ALERTA RI0, 2017; PMRJ, 2011. 
A variação temporal e espacial da precipitação no município do Rio de Janeiro permite identificar padrões de chuvas em função da sazonalidade cuja representação gráfica é obtida pelas médias mensais de cada estação pluviométrica.

A confecção das isoietas obtida com o programa Surfer 10 consiste da análise de valores pelo método de Krigagem, que utiliza dados tabulares e posições geográficas de modo a obter por regressão uma aproximação dos atributos de entrada. Ao utilizar o princípio de que unidades de análise mais próximas entre si são mais parecidas do que unidades mais afastadas, a Krigagem utiliza funções matemáticas de modo a acrescentar pesos maiores nas posições mais próximas aos pontos amostrais, e pesos menores nas posições mais distantes. Na combinação linear de dados são obtidos os novos pontos interpolados (JAKOB, 2002). Nesse contexto, foram utilizadas as coordenadas geográficas das estações pluviométricas identificadas pelo Sistema Alerta Rio, assim como os dados pluviométricos correspondentes.

As isoietas constituem escala espacial uniforme de maneira a facilitar a interpretação gráfica da distribuição espacial das médias mensais com valores de precipitação a partir de 10 $\mathrm{mm}$ e superiores a $240 \mathrm{~mm}$, intercalados a cada $10 \mathrm{~mm}$.

De forma bastante detalhada, a consistência dos dados foi realizada a partir de análise de registros observados de precipitação a cada 15 minutos, acumulada diária e mensal de cada estação e avaliação conjunta da Nota Técnica $n^{\circ} 8$ (IPP-Rio, 2012) e Tabela $n^{0} 513$ (IPP-Rio, 2015). Os dados brutos de precipitação obtidos do SAR-RJ foram comparados com os dados de precipitação consistidos do IPP-Rio (2015), cuja análise notou haver discrepância nos valores de precipitação acumulada dos totais mensais de determinados anos sem ultrapassar $\pm 3 \%$ de variação dos totais mensais de cada ano.

\section{RESULTADOS E DISCUSSÃO}

No período de 1999 - 2002 nota-se precipitação média anual entre 900 e 1000 mm abaixo cerca de $20 \%$ da média dos demais anos analisados. Os dados informam haver influência de eventos climáticos do El Niño e La Niña pela classificação ENOS, considerados nesse período de intensidade fraca e moderada (NOAA, 2015). Por outro lado, os anos de 1998, 2009 e 2010 apresentam precipitações acumuladas no ano acima da média do período analisado com classificação do fenômeno ENOS de moderado a forte (Gráfico 1). 
Gráfico 1 - Precipitação média mensal e anual das estações pluviométricas do Rio de JaneiroRJ (ALERTA RI0).

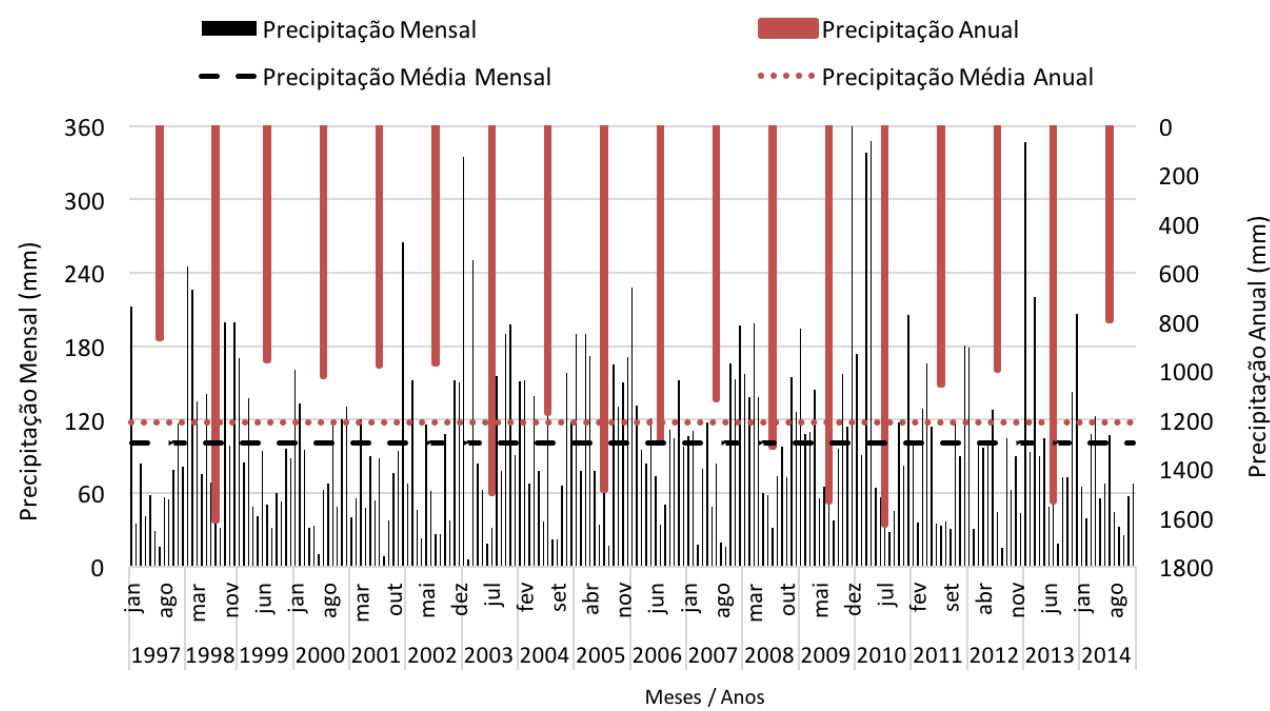

Fonte: ALERTA RIO (2015).

Por ser caracterizada por regiões de relevo acidentado, áreas preservadas de Mata Atlântica e fatores climáticos variados, a cidade do Rio de Janeiro apresenta diversidade no regime de chuvas, sobretudo pela influência de fenômenos atmosféricos de origem oceânica de grande escala, de modo a favorecer alterações na precipitação pluvial de forma concentrada em períodos característicos do ano. Por apresentar um relevo configurado de forma irregular, montanhoso a escarpado, especialmente devido a presença da Serra do Mar, a distribuição das chuvas tem performance determinante influenciada por fatores termodinâmicos (FRANCO et al., 2003)

Associado a fatores de uso e ocupação do solo, grandes maciços geográficos inseridos no contexto urbano constituem elementos físicos fundamentais na padronização do volume de precipitação pluvial de determinadas regiões da cidade, especialmente na formação de chuvas orográficas e de verão.

A proximidade da região litorânea e a presença da Mata Atlântica tornam maiores os índices pluviométricos na região do litoral sul fluminense, enquanto o afastamento ao interior do continente, tende a reduzir os índices médios pluviométricos (SOARES, FRANCISCO, DE CARVALH0, 2003).

Na análise da série histórica da precipitação pluviométrica média entre 1997 e 2014, e entre 2001 e 2014 e 2011 e 2014, a depender dos dados disponíveis de cada pluviômetro, das 33 estações do SAR-RJ os resultados informam sazonalidade mensal na distribuição das chuvas 
na cidade do Rio de Janeiro-RJ, com volumes precipitados acima da média nos meses de janeiro, março, abril, outubro, novembro e dezembro.

De forma geral e com característica bastante peculiar, o mês de fevereiro chove entre 5 e $10 \%$ a menos que esses meses de todas as estações analisadas. A precipitação mensal média de todas as estações analisadas oscila de forma sazonal durante os anos analisados, com volume precipitado acentuado próximo ou acima da média entre os meses de outubro e abril, correspondente as estações de primavera e verão, e os demais meses entre maio e setembro com precipitações entre 40 e 80 mm (Gráfico 2).

Gráfico 2 -Precipitação média mensal de série histórica de 18 anos do SAR-RJ.

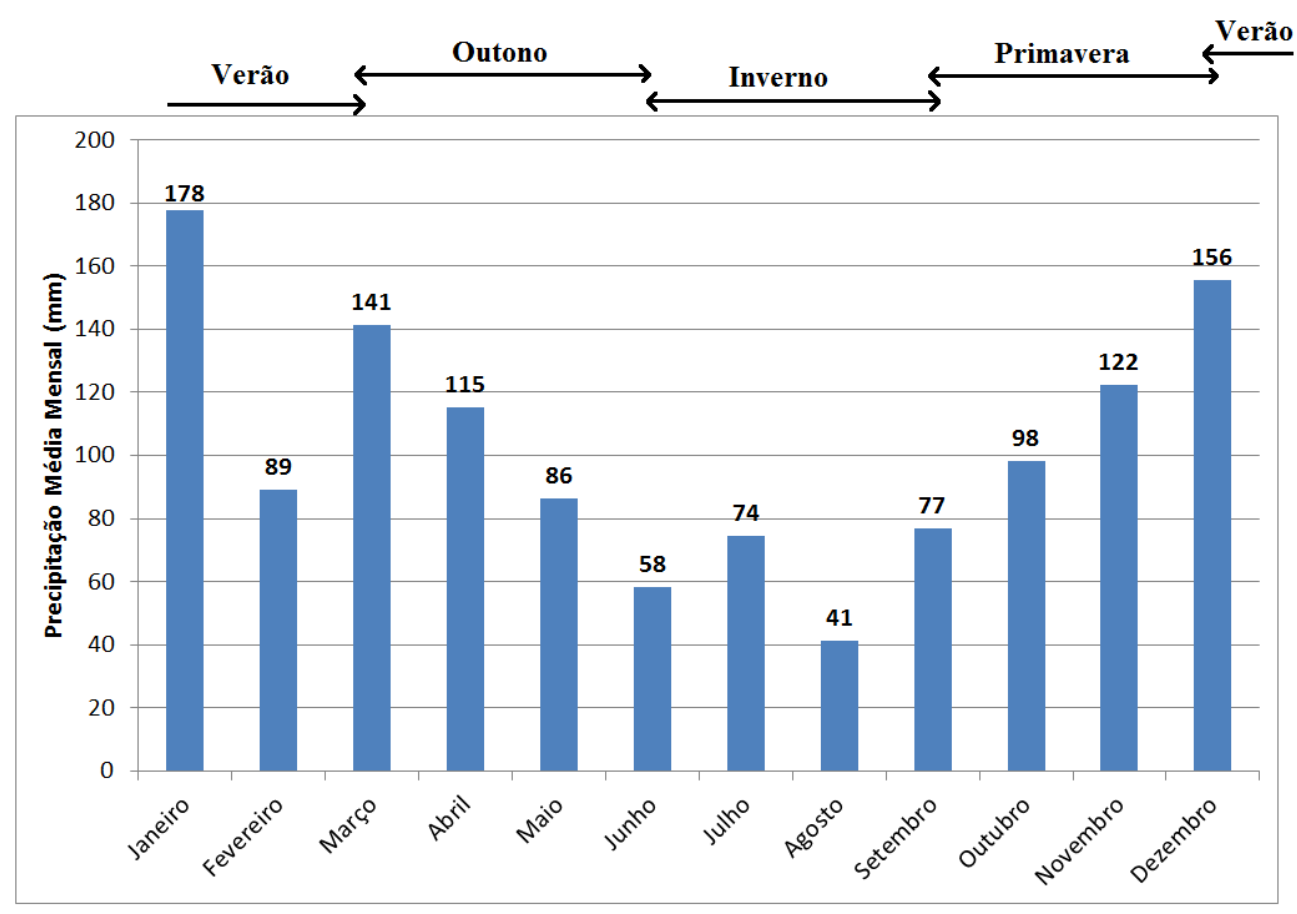

Fonte: Próprio autor.

As isoietas mensais caracterizam variabilidade pluviométrica a partir das estações do SAR-RJ, de modo a identificar padrões no comportamento das chuvas de forma localizada. 0 relevo acidentado e diversificado da cidade, na presença dos maciços Gericinó Mendanha, ao norte, e da Pedra Branca, a oeste, contribui para a grande variabilidade espacial da precipitação (DERECZYNSK, DE OLIVEIRA; MACHAD0, 2009).

As Figuras 4, 5 e 6 apresentam as isoietas mensais do município do Rio de Janeiro obtidas a partir do SAR-RJ. As curvas de precipitação apresentam relativa padronização ocasionada sobretudo pela presença de estações pluviométricas em regiões com características de relevo acentuado e alterações 
0 mês de janeiro se caracteriza por ser o mais chuvoso do ano praticamente em todo 0 município do Rio de Janeiro, com precipitações médias acima de $240 \mathrm{~mm}$, como observado na região do Alto da Boa vista, e superiores a $230 \mathrm{~mm}$ na estação Av.Brasil/Mendanha. A precipitação média acumulada nesse mês é superior $140 \mathrm{~mm}$ em toda a cidade (Gráfico 3).

Embora considerado de período úmido, o mês de fevereiro apresenta interrupção na sequência de meses com índices pluviométricos característicos de estação chuvosa ou de verão, com registros observados na cidade do Rio entre 40 e 120 mm (Gráfico 3).

Os meses de março e abril apresentam acentuado padrão chuvoso com precipitações médias superiores a $100 \mathrm{~mm}$ em todo o município. No entanto, é um período de transição das estações de verão e outono, de modo que determinadas regiões apresentam precipitações menores do que 70 m, como ao norte do município, nas proximidades de Irajá (Gráfico 3).

Gráfico 3 - Precipitação média mensal entre janeiro e abril no Rio de Janeiro-RJ (ALERTA RI0).
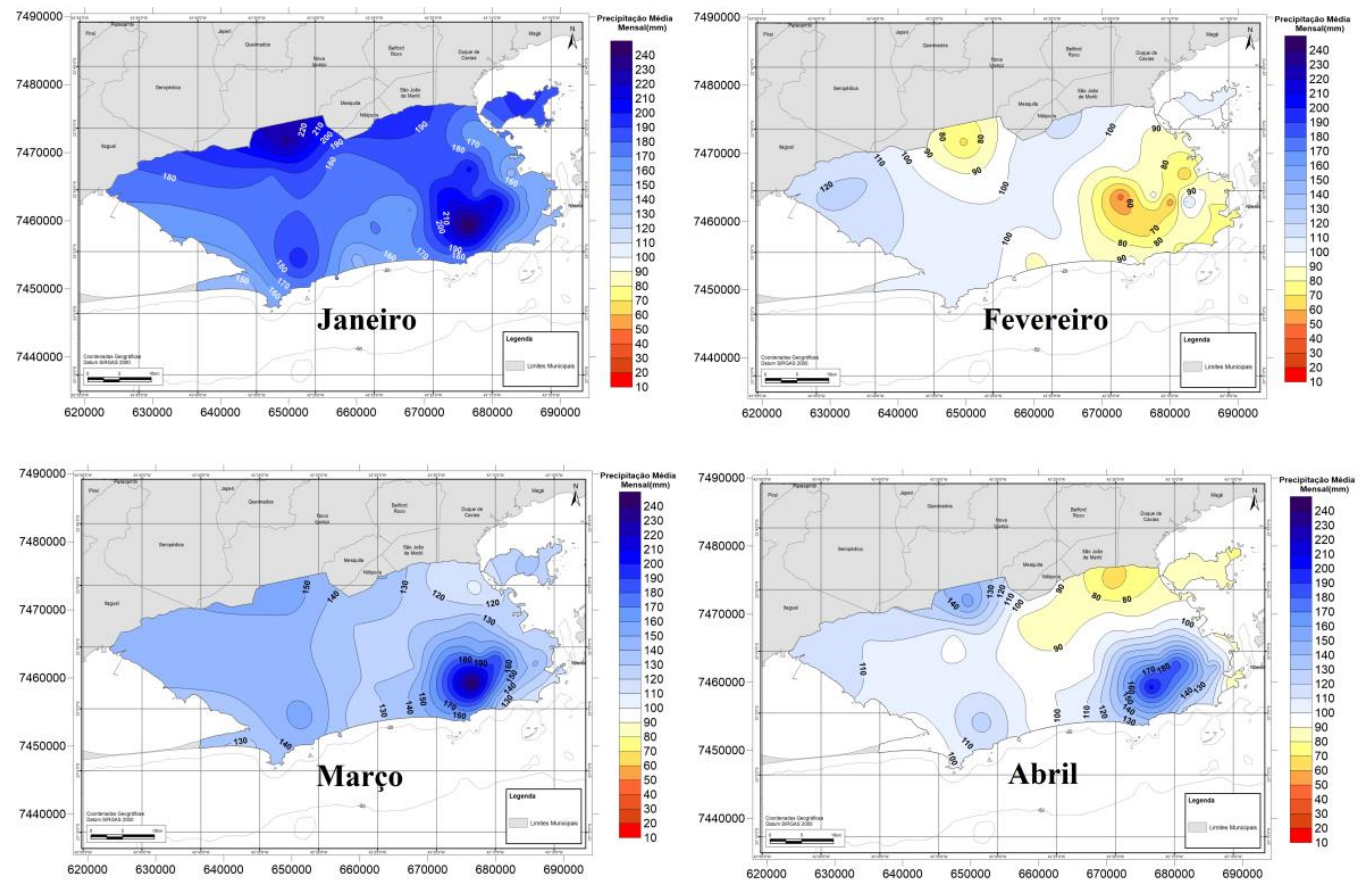

Fonte: Próprio autor.

De forma geral, para todos os postos pluviométricos analisados, o trimestre mais (menos) chuvoso é nov-jan (jun-ago) (DERECZYNSK, et al. 2009). Maio e junho caracterizam períodos de transição com tendência de comportamento mais seco do que nos meses iniciais do ano, com precipitações acumuladas inferiores a $50 \mathrm{~mm}$, como nas regiões de Irajá e Penha. Regiões com predomínio de mata atlântica apresentam precipitação média acima de 110 e 200 mm, como na estação da Grota Funda e no Alto da Boa Vista, respectivamente (Gráfico 4). 
0 início do inverno em julho apresenta regiões com divergência de tendência de comportamento correspondente ao período seco. As regiões da Rocinha, Barra/Barrinha, Alto da Boa Vista, Vidigal, Jardim Botânico e Grota Funda, apresentam precipitações médias mensais entre 90 e $240 \mathrm{~mm}$. Demais regiões, especialmente ao norte e noroeste da cidade há predomínio de comportamento mais seco com precipitações mensais acumuladas inferiores a $70 \mathrm{~mm}$ e próximo de $40 \mathrm{~mm}$ nas regiões de Irajá, Penha, Ilha do Governador, Bangu e Anchieta (Gráfico 4).

Agosto se caracteriza como o mês mais seco do ano, com precipitações médias de 20 mm nas regiões de Irajá, Penha, São Cristóvão e Av. Brasil/Mendanha. Demais regiões apresentam precipitações inferiores a $50 \mathrm{~mm}$ (Gráfico 4).

Gráfico 4 - Precipitação média mensal entre maio e agosto no Rio de Janeiro-RJ (ALERTA RI0).
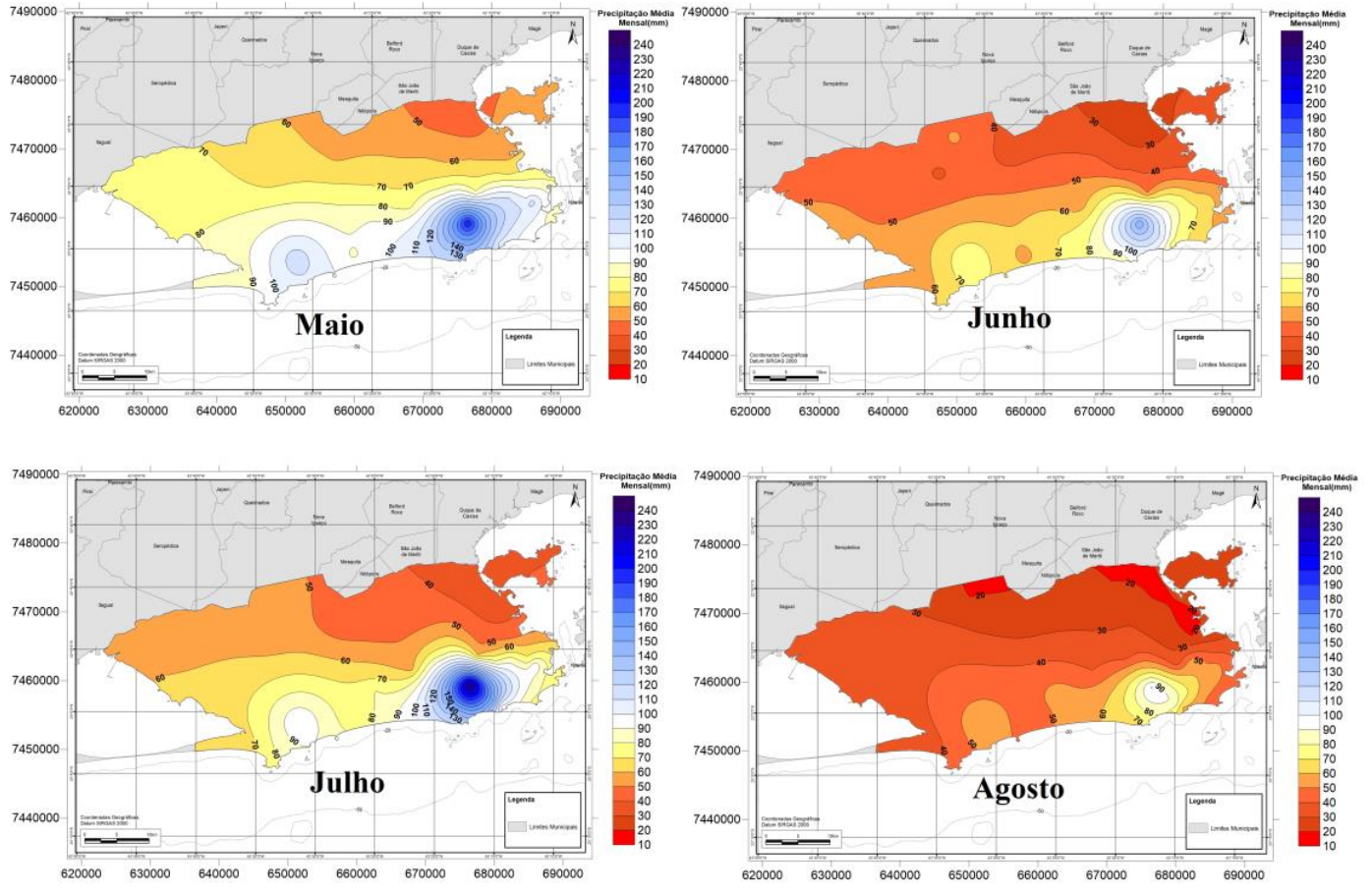

Fonte: Próprio autor.

0 mês de setembro ilustra o término do período seco e do inverno. Regiões como Rocinha, Alto da Boa Vista e Barra/Barrinha apresentam precipitações superiores a $140 \mathrm{~mm}$, porém demais estações registram precipitações inferiores a $70 \mathrm{~mm}$ (Gráfico 5).

Outubro apresenta o início da primavera com período úmido acentuado por precipitações médias superiores a $80 \mathrm{~mm}$ em todo o município. Regiões como Tijuca, Jardim Botânico e Grota Funda registram precipitações acima de $120 \mathrm{~mm}$ e, $150 \mathrm{~mm}$ de chuva 
acumulada no mês pode ser observado na Rocinha, Alto da Boa Vista e Barra/Barrinha (Gráfico $5)$.

0 final da primavera e o início do verão entre novembro e dezembro há uma tendência acentuada nos índices pluviométricos com precipitações médias acima de $140 \mathrm{~mm}$ em cada estação. Regiões como Rocinha, Santa Teresa, Barra/Barrinha, Est. Grajaú/Jacarepaguá, Anchieta, Alto da Boa Vista e Laranjeiras, as precipitações superam 170 mm, inferior apenas aos dados observados na Tijuca com precipitações acumuladas no mês de até $190 \mathrm{~mm}$ (Gráfico $5)$.

Gráfico 5 - Precipitação média mensal entre setembro e dezembro no Rio de Janeiro-RJ (Alerta Rio).
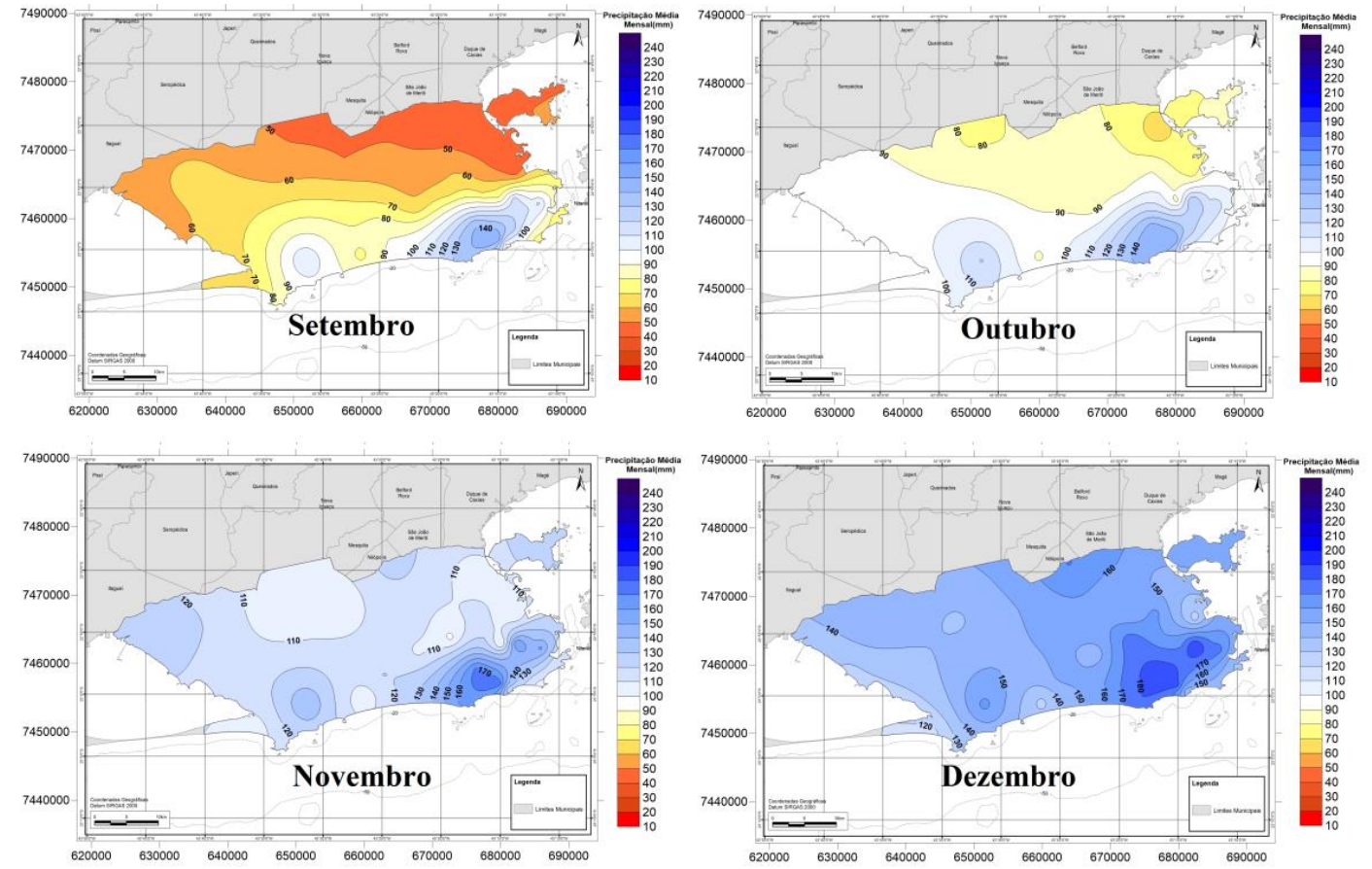

Fonte: Próprio autor.

As regiões delimitadas pelas estações Barra/Barrinha, Alto da Boa vista, Tijuca, Jardim Botânico, Rocinha e Vidigal, tendem a concentrar no mês grande volume de precipitação pluvial nos anos observados. Este padrão é ilustrado nas isoietas dos meses de abril, julho, setembro e novembro. A região da estação da Grota Funda também apresenta comportamento mais chuvoso quando comparada às regiões circunvizinhas, devido às proximidades do Parque Estadual da Pedra Branca, composto por remanescente de Mata Atlântica. Os bairros de Irajá, Penha e Ilha do Governador, ao norte da cidade, constituem locais que apresentam períodos mais secos no inverno que as demais regiões do município. 


\section{CONCLUSÃO}

Este trabalho permite concluir que a variabilidade espacial e temporal da precipitação pluviométrica avaliada nos mapas de isoietas mensais demonstra distinção na distribuição do padrão de chuvas na cidade do Rio de Janeiro, embora represente sazonalidade associada às características das estações do ano.

Os fatores geoclimáticos e a urbanização na região auxiliam na formação da precipitação e na variabilidade pluviométrica de forma característica na cidade do Rio de Janeiro, sob forte influência da disposição do relevo, remanescente de Mata Atlântica e costa oceânica.

$\mathrm{Na}$ continuidade deste trabalho, recomenda-se desenvolver análise estatística aprofundada dos valores observados de precipitação pluviométrica e cálculo de indicadores de extremos climáticos de modo a avançar no conhecimento do regime de chuvas na região.

\section{AGRADECIMENTOS}

Ao Programa Institucional de Bolsas de Iniciação Científica pela concessão de bolsa de Iniciação Científica PIBIC 2016-2018, ao CNPq Edital Chamada Universal MCTI/CNPq nº 14/2014, Faixa A Processo no 457688/2014-9, a Fundação Carlos Chagas Filho de Amparo à Pesquisa do Estado do Rio pelo Projeto ADT1/2015-2 nº do Processo E-26/010.00185/2016 pelo apoio ao desenvolvimento deste trabalho.

\section{REFERÊNCIAS BIBLIOGRÁFICAS}

ALERTA RIO. Sistema Alerta Rio da Prefeitura do Rio de Janeiro. Centro de Operações Rio. Rio de Janeiro, RJ. Disponível em: http://alertario.rio.rj.gov.br/. Acesso em 13 fev 2017.

ARAÚJO, M.F.C.; GUIMARÃES, E.C.; CARVALHO, D.F.; ARAÚJO, L.B. Precipitação pluviométrica mensal no estado do Rio de Janeiro: sazonalidade e tendência. Biosci. J., Uberlândia, v.25, n.4, p.90-100, Jul-Aug/ 2009.

BRITTO, F. P.; BARLETTA, R.; MENDONÇA, M. Regionalização Sazonal e Mensal da Precipitação Pluvial Máxima no Estado do Rio Grande do Sul. Revista Brasileira de Climatologia, v.2, p.35-5l, dez. de 2006.

COSTA, H. C.; MARCUZZO, F. F. N.; FERREIRA, 0. M.; ANDRADE, L.R. Espacialização e Sazonalidade da Precipitação Pluviométrica do Estado de Goiás e Distrito Federal. Revista Brasileira de Geografia Física, v.5, n.l, p.87-100, 2012. 
DERECZYNSKI, C. P.; DE OLIVEIRA, J. S.; MACHADO, C. O. Climatologia Da Precipitação No Município Do Rio De Janeiro. Revista Brasileira de Meteorologia, v.24, n.1, p.24-38, 2009.

FRANCO, N. J. N. et al. A Influência da Zona de Convergência do Atlântico Sul (ZCAS) no Transporte de Radionuclídeos na Região de Angra dos Reis, usando Modelagem Numérica. In: III CONGRESSO INTERAMERICANO DE QUALIDADE DO AR, AIDIS. 2003, Canoas (RS). Anais eletrônicos. Canoas: Asociación Interamericana de Engenieria Sanitaria y Ambiental, 2003.

HILLESHEIM, W. T.; NEVES, L. 0. Análise Frequencial e Distribuição Temporal das Chuvas na Região de Rio do Sul/ SC. Revista Ciência e Natura, Santa Maria, v.37 Ed. Especial SIC, p.119-124. 2015.

IBGE. Estimativas da população residente no brasil e unidades da federação com data de referência em $1^{0}$ de julho de 2016. Instituto Brasileiro de Geografia e Estatística. Cidades. Disponível em : http://www.cidades.ibge.gov.br/xtras/home.php. Acesso em 03 ago 2016.

IPP-Rio- INSTITUTO PEREIRA PASSOS. Série histórica de índices pluviométricos das 32 estações da cidade do Rio de $\begin{array}{llllll}\text { Janeiro } 2000-2010 & - & \text { notas } & \text { metodológicas. } & 2012 . & \text { Disponível }\end{array}$ http://www.armazemdedados.rio.rj.gov.br/arquivos/3234_nt8_s\%C3\%A9rie\%20hist\%C3\%B3rica\%20de\%20\%C3\%AD ndices\%20pluviom\%C3\%A9tricos.PDF. Acesso em 12 fev 2017.

IPP-Rio- INSTITUTO PEREIRA PASSOS. Tabela $\mathrm{n}^{\circ}$ 513. Total anual, média mensal e total mensal das precipitações pluviométricas, segundo as estações telepluviométricas automáticas do Sistema de Alerta de Deslizamentos ALERTA RI0 - GE0-RI0 - Rio de Janeiro 1997-2015. 2015. Disponível em: http://www.armazemdedados.rio.rj.gov.br/arquivos/513_precipita\%C3\%A7\%C3\%B5es\%20pluviom\%C3\%A9tricas\%20 -1997\%20a\%202015.XLS. Acesso em 12 fev 2017.

JAKOB, A. A. E. A Krigagem como Método de Análise de Dados Demográficos. In: ENCONTR0 DA ASSOCIAÇÃO BRASILEIRA DE ESTUDOS POPULACIONAIS, 13, Ouro Preto, 2002.

KOTTEK, M.; GRIESER, J.; BECK, C.; RUDOLF, B.; RUBEL, F. World map of the Köppen-Geiger climate classification updated. Meteorologische Zeitschrift, v.15, n.3, p.259-263, 2006.

LOUREIR0, G. E.; FERNANDES, L. L. Variação da Precipitação por Método de Interpolação Geoestatística. Revista Ambiente \& Água, Taubaté, v.8, n.2, p.77-87, 2013.

MARCUZZ0, F. F. N.; GOUlaRTE, E. R. P.; MELO, D. C. R.; FILHO, R. F. P.; CARDOSO, M. R. D. Mapeamento Espacial, Temporal e Sazonal das Chuvas no Bioma Cerrado do Estado do Tocantins. In: SIMPÓSIO BRASILEIR0 DE SENSORIAMENTO REM0T0, 15, Curitiba: INPE, 2011. p.5217.

NOAA. National Weather Service. Climate Prediction Center. Nov, 2015. Disponível em: http://www.cpc.ncep.noaa.gov/products/analysis_monitoring/ensostuff/ensoyears.shtml. Acesso em 03 Mar 2017.

PMRJ. PREFEITURA DA CIDADE DO RIO DE JANEIR0. Plano Diretor de Desenvolvimento Urbano Sustentável do Município do Rio de Janeiro. Mapa 02. Hipsometria, Hidrografia e Sub-Bacias Hidrográficas: Brasil 2011. Rio de Janeiro: PMRJ, 2011.

RADHA, L. \& SUDHAKARAN, G. Spatial and Temporal Variation of Rainfall in Iraq. SSRG International Journal of Applied Physics (SSRG-IJAP) - v.2, n.2, March/April 2015.

SERRA, A. B. Clima da Guanabara. Boletim Geográfico, Fundação Instituto Brasileiro de Geografia, ano 29, n.214, jan/fev 1970, p.80-111, 1970.

SOARES, F. S.; FRANCISCO, C. N.; DE CARVALHO, C. N. Análise dos Fatores que Influenciam a Distribuição Espacial da Precipitação no Litoral Sul Fluminense, RJ. In: SIMPÓSI0 BRASILEIR0 DE SENSORIAMENTO REM0T0, Goiânia: INPE, 12, p.3365-3370, 2005. 